DOI 10.37882/2223-2974.2020.10.40

\title{
ЗАМЕДЛЕНИЕ РОСТА МИРОВОЙ ЭКОНОМИКИ КАК ОСНОВНОЙ ФАКТОР УСКОРЕНИЯ ПРОМЫШЛЕННОЙ РЕВОЛЮЦИИ
}

\section{SLOWING DOWN THE GROWTH OF THE GLOBAL ECONOMY AS THE MAIN FACTOR IN ACCELERATING THE INDUSTRIAL REVOLUTION}

D. Havin

P. Bekker

Summary: The article analyzes the current trends in innovative activity of countries and regions. Particular emphasis is placed on the importance of not only innovation as such, but the predominant importance of introducing new technologies into the economies of individual countries, which increases the competitiveness and well-being of national economies. The aggravating economic crisis caused by the spread of a new coronavirus infection creates urgent tasks for the world community. Based on the analysis of existing threats and restrictions that impede the development of the domestic economy, proposals are made for overcoming the current unfavorable situation. Existing economic realities should not be an obstacle, but, on the contrary, should be a catalyst and a signal for government and business to rebuild the existing domestic economic system and interaction, following the example of developed countries. Including, with the introduction of technology synthesis, automation of production, logistics processes, which are based on innovation management of innovative processes. The considered solutions to improving the domestic economy will accelerate the transition from a "mining" economy to an economy with a predominant share of innovative potential, which is one of the key components for the transformation of the commodity economy. The results presented in the article are based on the works of both domestic and foreign scientists.

Keywords: stagnation, technological innovation, the fourth industrial revolution, innovation management.

\author{
Хавин Дмитрий Валерьевич \\ ФГБОУ ВО «Нижегородский государственный \\ архитектурно-строительный университет», \\ Нижний Новгород \\ odonngasu@yandex.ru \\ Беккер Павел Райнгольдович \\ ФГБОУ ВО «Нижегородский государственный \\ архитектурно-строительный университет», \\ Нижний Новгород \\ BeckerPR@yandex.ru
}

Аннотация: В статье проведён анализ актуальных тенденций инновационной активности стран и регионов. Особый акцент сделан на значимости не только инноваций как таковых, а преобладающей значимости внедрения новых технологий в экономику отдельных стран, что повышает конкурентоспособность и благосостояние национальных экономик. Усугубляющийся экономический кризис, вызванный распространением новой коронавирусной инфекции, формирует актуальные задачи для мирового сообщества. На основе проведенного анализа существующих угроз и ограничений, препятствующих развитию отечественной экономики, даются предложения для выхода из сложившейся неблагоприятной ситуации. Существующие экономические реалии не должны являться препятствием, а, наоборот, должны стать катализатором и сигналом для правительства и бизнеса по перестроению существующей отечественной системы хозяйствования и взаимодействия на примере развитых стран. В том числе, с внедрением синтеза технологий, автоматизации производственных, логистических процессов, в основе которых инновации управления инновационными процессами. Рассматриваемые пути решения по оздоровлению отечественной экономики позволят ускорить переход от «добывающей» экономики к экономике с превалирующей долей инновационного потенциала, что является одной из ключевых составляющих для трансформации сырьевой экономики. Результаты, приведенные в статье, основываются на трудах как отечественных, так и зарубежных ученых.

Ключевые слова: стагнация, технологические инновации, четвёртая промышленная революция, управление инновациями.

квартале 2020 года сократился на 7\% по, что не наблюдалось за всю историю современной экономики Китая [15]. фекции является главной темой для экономистов и учёных на ближайшие месяцы, поскольку число заражений в мире экспоненциально растет, оказывая все большее влияние не только на отдельные регионы и страны, но и в целом на мировую экономику, деловую активность. В настоящее время множество стран предприняли предупреждающие меры по недопущению распространения вируса. Сейчас наиболее точно можно оценить последствия данных ограничений на примере экономики Китая. В результате предпринятых ограничительных мер около 70\% предприятий КНР все еще не функционирует в прежнем масштабе, а ВВП в первом
Федеральная резервная система США и центральные банки развитых стран предпринимают масштабные шаги для стабилизации мировой экономики. В марте 2020 года ФРС США снизила ставку по федеральным фондам до рекордного уровня и объявила о беспрецедентной поддержке экономики и населения в 2 трлн долларов. В дальнейшем рассматривается возможность снижения ставки до отрицательного значения и дополнительные финансовые вливания в экономику страны. Фондовые рынки США, России, Китая и других стран подверглись 
массовой волне распродаж за последние несколько лет, падение тысяч бумаг достигло дневного лимита всего за несколько минут торгов. Китай является крупнейшим мировым импортером нефти с 2016 года, когда он обошел США, и, таким образом, изменение объема спроса в этой стране может оказывать огромное влияние на глобальный рынок. Быстрое распространение вируса за пределы Китая привело к резкому сокращению перемещения населения и туризма, а также к отмене деловых и развлекательных мероприятий по всему миру, поскольку «социальное дистанцирование» стало реальностью. Потребление нефти в Китае составляет порядка 14 млн баррелей в сутки (около 15\% общемирового спроса), что эквивалентно совокупным потребностям Франции, Германии, Италии, Испании, Великобритании, Японии и Южной Кореи [4].

Международное рейтинговое агентство Fitch Ratings даёт неутешительные прогнозы, что продолжающаяся пандемия вируса не только обваливает фондовые рынки, сея панику среди инвесторов, но и может привести к дальнейшему падению спроса на нефть, к усилению перепроизводства из-за увеличения добычи в Бразилии, Норвегии, США, Саудовской Аравии (рис.1). «Размер профицита будет зависеть от продолжительности вспышки и способности стран ОПЕК+ скорректировать объемы добычи в случае необходимости. Мы ожидаем, что цены на нефть останутся крайне нестабильными в 2020 году, а геополитическая напряженность и экономические настроения будут ключевыми факторами» [8].

Негативное развитие ситуации отразится и на банковском секторе, в группе наивысшего риска оказались банки стран бывшего СССР, а именно Украины, России, Казахстана, Армении, Азербайджана, Белоруссии и Грузии. «Степень давления на банки будет зависеть от масштабов и продолжительности экономического спада, конкретных рисков для национальных экономик и внешнего финансирования (например, снижения цен на нефть, доходов от туризма или денежных переводов), политических мер национальных властей и бизнес-профилей отдельных банков» [9]. Международное агентство изменило прогноз для этих банков на «негативный» вместо «стабильный». Все негативные факторы в настоящее время в мировой экономике по оценкам экспертов приведут к замедлению роста ВВП и даже возможной стагнации [9]. Рейтинговые агентства почти вдвое сократили базовые прогнозы глобального роста экономики на 2020 год - до 1,3\% с 2,5\% в декабре 2019 года, что в абсолютном выражении составляет на 850 млрд долларов ниже, чем в предыдущем прогнозе [6].

Всё вышесказанное формирует новые задачи перед мировым сообществом, и чем скорее они будут разрешены, тем безболезненнее и стабильнее национальные экономики, системы хозяйствования будут откликаться на будущие угрозы. Эпидемия нанесла существенный урон всей мировой экономике, но больше всего пострадала отрасль туризма, доля которой составляет более чем $2 \%$ в мировом ВВП. Аналогичная ситуация и с малым бизнесом, розничной торговлей товаров длительного пользования. Во Франции, Италии, Испании распоряжением властей уже закрыта любая торговля, кроме необходимой для выживания. В странах где нет жёстких запретов население проявляет личную ответственность и старается минимизировать походы в магазины, досуговые центры, публичные места, при этом потребление товаров длительного пользования в развитых странах составляет более 6\% ВВП.

Нанесенный эпидемией удар по странам показал, что необходим кардинальный пересмотр не только вопросов социального обеспечения граждан, но и в целом механизма хозяйствования. Правительства и бизнес-сообщество в настоящее время переориентируют свои возможности и инвестиционные потоки для развития технологий будущего уже сегодня. Так, будут исчезать привычные профессии, изменится способ взаимодействия коллег между собой, привычные формы обучения, проведения совещаний трансформируются исключи-

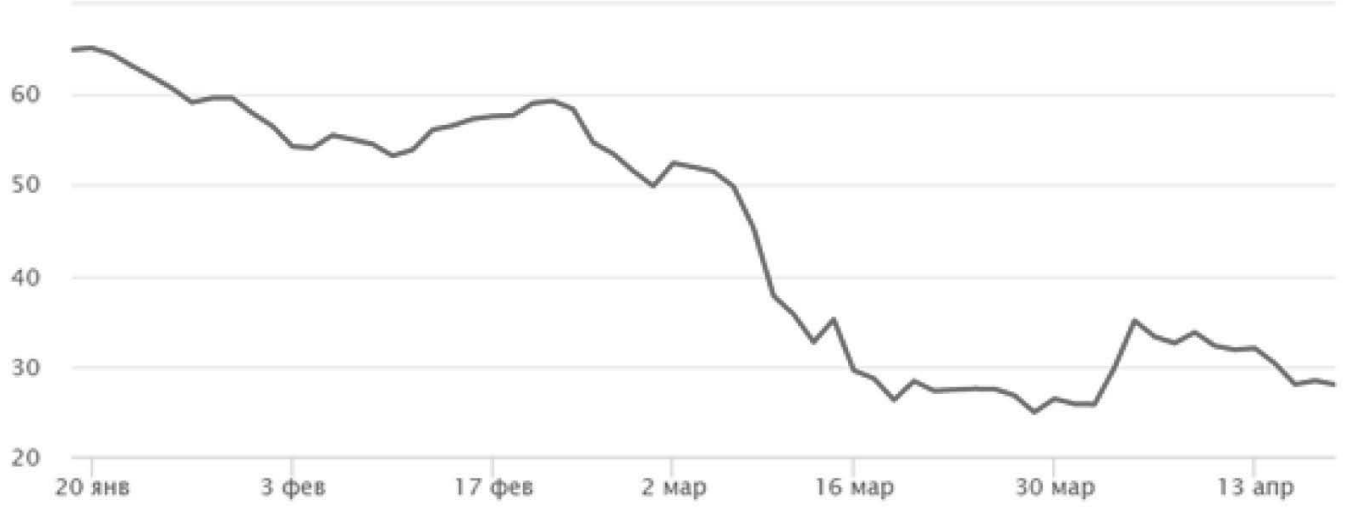

Рис. 1. Динамика цен на нефть марки Brent в USD за баррель (данные https://yandex.ru/news/quotes/1006.html) 
тельно в дистанционную форму. Мощный стимул развития после спада эпидемии получит автоматизация всех отраслей от торговли до проведения собеседований, розничная торговля ещё больше уступит своё место онлайн магазинам. Наравне с автоматизацией процессы роботизации большинства производственных процессов, а также логистики и складирования, позволят избежать влияния человеческого фактора, который способствует дестабилизации экономической ситуации и нарушению хозяйственных цепочек в критические моменты, как показал опыт настоящего кризиса. Человеческая роль в экономике останется, и она возрастёт, однако способы построения взаимодействия существенно изменятся. В скором времени мы сможем наблюдать синтез технологий, где часть человеческого труда будет заменена роботами (доставка, перегрузка, транспортировка, хранение, учёт и др.) или дополнена ими. В случае возникновения аналогичных кризисных ситуаций человек смог бы дистанцироваться и работать вне зоны возможного неблагоприятного воздействия.

Таким образом, мы можем говорить, что прогнозируемая четвёртая промышленная революция не только началась, но и под влиянием существующего кризиса её развитие будет проходить экспоненциальными темпами [10]. По аналогии с предыдущими промышленными революциями трансформация экономики будет приводить к отмиранию ряда профессий, но если после второй и третьей промышленной революции исчезновение массовых профессий привело к появлению новых, то сейчас ситуация кардинально иная. Внедрение инноваций во всех сферах жизни общества ускорится, появление роботизированных решений множества задач приведёт к снижению потребности в первую очередь в низкоквалифицированном труде и в тех профессиях, где принятие решений построено по заранее известным алгоритмам, а их перечень очень широк (бухгалтера, юристы, банковские служащие и др.). Мировой рынок труда значительно деформируется, что, возможно, приведёт к массовой безработице, на примере великой депрессии в США или даже масштабнее [1]. Настоящее потрясение коснётся в первую очередь развивающихся стран, где представителей рабочих профессий значительно больше в удельном весе всего трудоспособного населения, в сравнении с развитыми странами.

Несмотря на глобальный экономический спад, низкий рост производительности труда в большинстве стран развитие и поддержка инноваций активно реализуется, об этом свидетельствуют объёмы финансирования наукоёмких производств и инвестиций в НИОКР, рост опережает развитие мировой экономики за последние 20 лет более чем вдвое (рис.2).

В 2018 г. Общемировой объем государственных расходов на НИОКР возрос более чем на 5\%, а объем расходов в бизнес сфере на инновации увеличился на 7,5 \%, что является самым крупным приростом с 2011 г [13]. Распределение инноваций также меняется, если около 5 лет назад превалировала высокая доля расходов на инновации только в развитых странах с высокими доходами населения, то сейчас сдвиг осуществляется к стра-

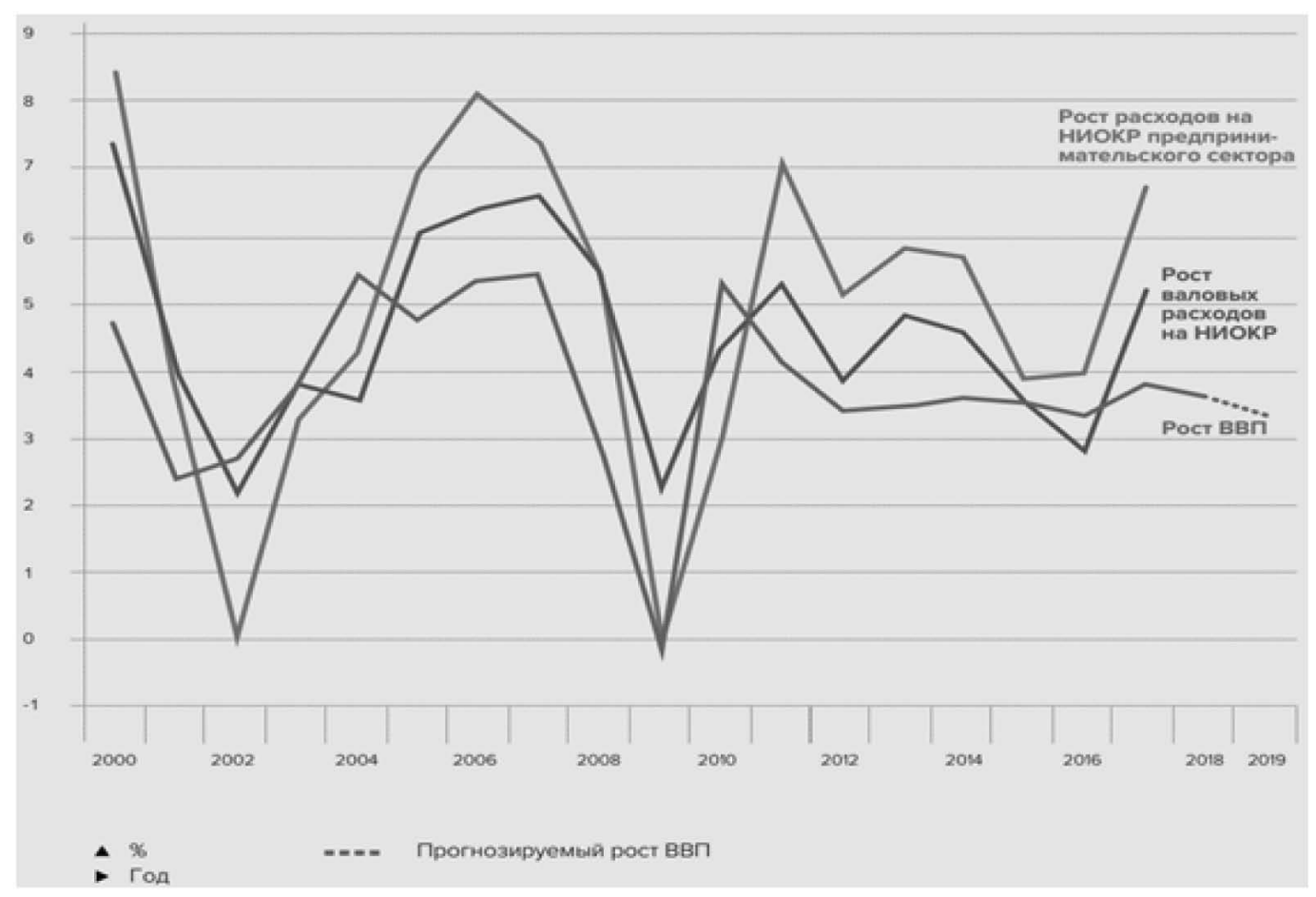

Рис.2. Сравнение роста расходов на НИОКР с общим развитием экономики [13] 
нам со средним доходом. Но несмотря на это лидерами в инновационном секторе по-прежнему являются лишь некоторые страны по регионам (рис.3). Инновационный потенциал, как и ранее характеризуется сильной дифференциацией по странам и перейти в сильный инновационный кластер довольно сложно, но несмотря на это активные усилия прилагают Китай и, в некоторой мере, Индия, Бразилия и Российская Федерация. Общие усилия отдельны стран в итоге повлияет на глобальный инновационный ландшафт.
Для перехода к экономической модели с преобладанием инновационного потенциала Российской Федерации потребуются годы, однако существующий кризис не должен быть препятствием, а наоборот, должен стать катализатором и сигналом для правительства и бизнеса, чтобы перестроить существующие системы хозяйствования и взаимодействия по примеру развитых стран. Однако результаты инновационной деятельности в сравнении с уровнем доходов свидетельствуют о недостаточности предпринимаемых государством мер

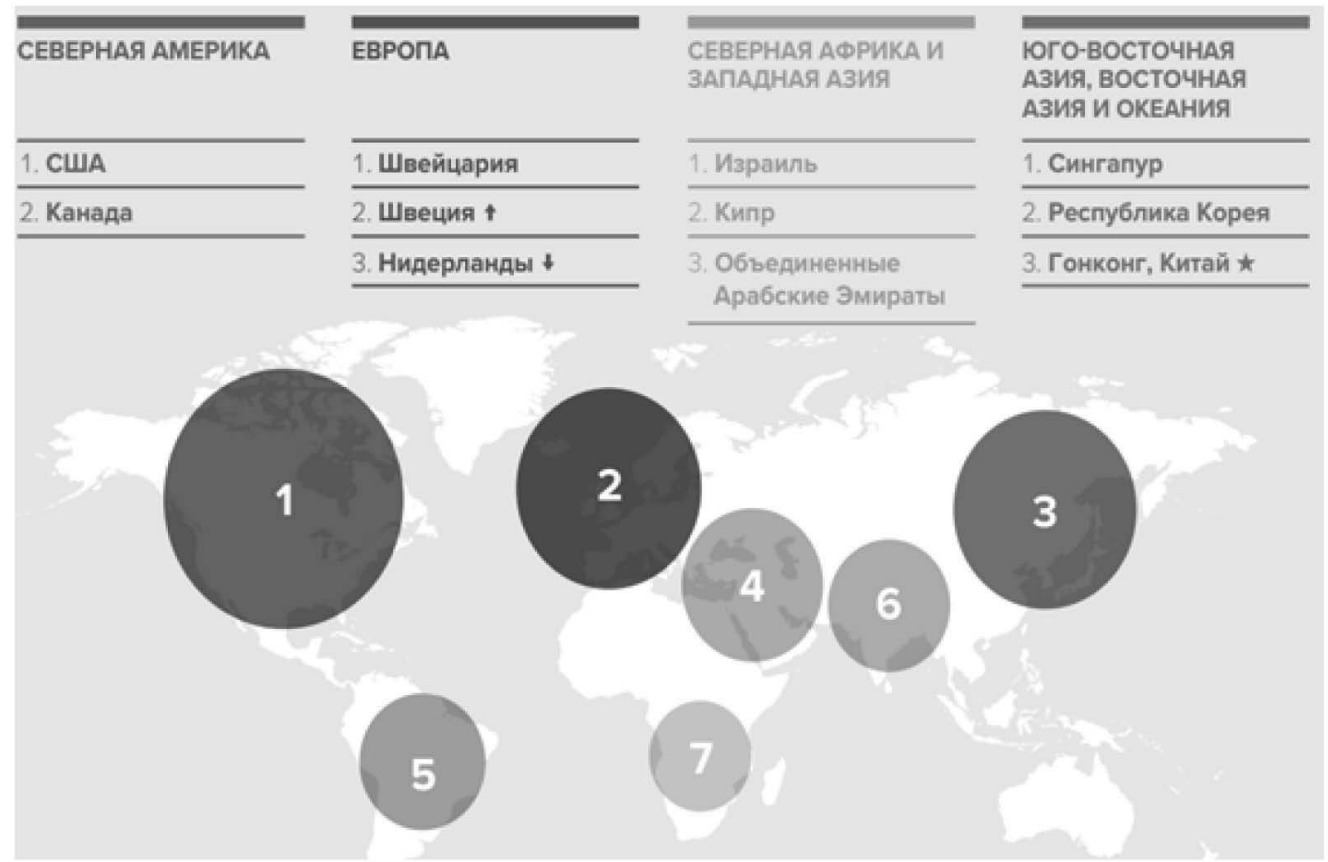

Рис.3. Мировые лидеры в области инноваций за 2019 г (данные глобального инновационного индекса https://www.globalinnovationindex.org/)

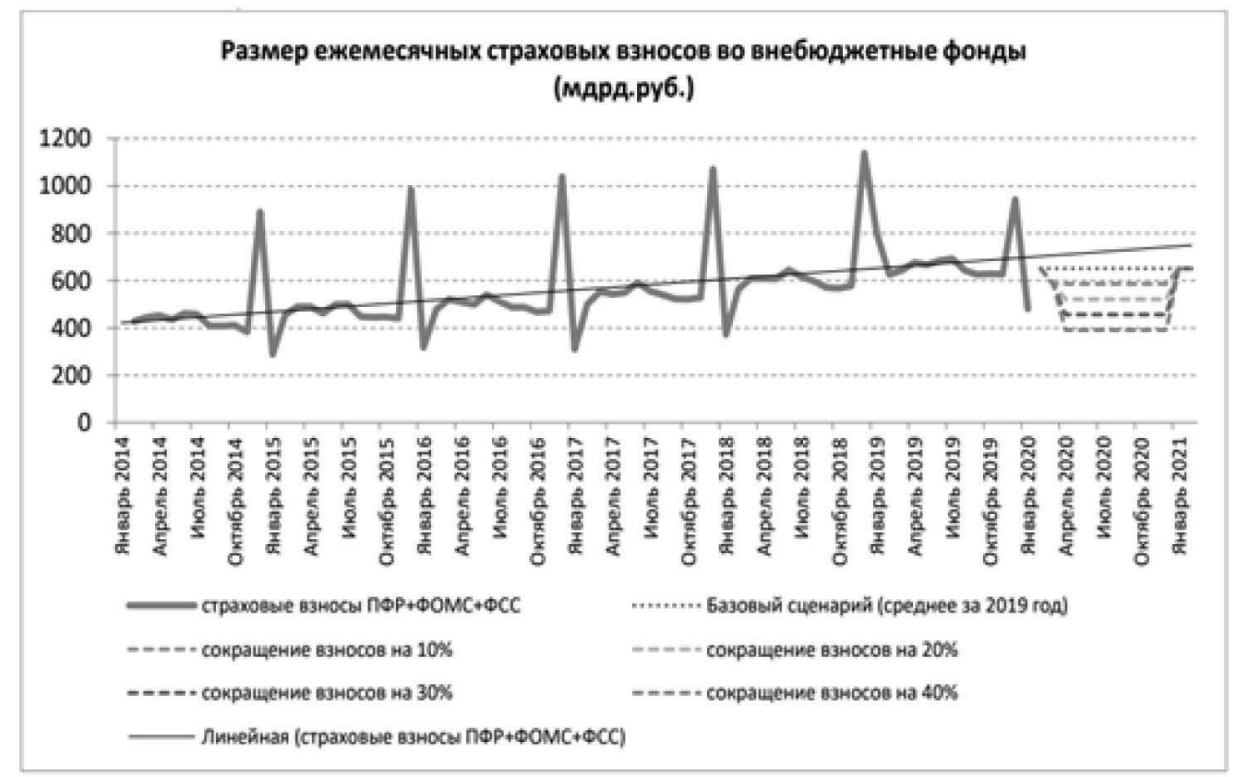

Рис. 4. Размер ежемесячных страховых взносов во внебюджетные фонды (мдрд.руб.) (данные Институт социальной политики НИУ ВШЭ 2020 г.) 
для поддержания отечественных компаний в области инноватики и инновационных разработок. Общие результаты ниже ожидаемых, по данным ряда исследований [12] Российская Федерация по доли инновационной деятельности в сравнении с доходами уступает таким странам как Албания, Ямайка, Румыния, Ливан. При этом качественная сторона инноваций в России позволяет не отстать безнадёжно от развитых стран, РФ в тройке лидеров стран со средним уровнем доходов по качеству инноваций, среди которых также Китай, Индия. Рейтинг качества инноваций основан на уровне образования, запатентованных изобретениях, а также на индексе цитируемости, что позволяет объективно оценить качественную сторону инноваций по странам.

Экономика Российской Федерации относится к развивающимся, а значит в большей степени будет подвержена серьёзным испытаниям под влиянием принятых ограничительных мер в результате пандемии, деловая активность только за первую неделю введённых ограничений снизилась на $16 \%$, а общее падение сравнимо с уровнем 2014 годом [7]. От экономической активности напрямую зависит ряд важных факторов, в том числе размер фонда оплаты труда, количество рабочих мест, уровень безработицы, уровень доходов, уровень спроса, уровень потребления и т.д. - по всем этим показателям наблюдается негативная тенденция. Это в свою очередь окажет дополнительную нагрузку на бюджет и внебюджетные фонды. По данным исследования (рис. 4), с начала марта 2020 года прогнозируется существенное ежемесячное снижение в том числе и страховых взносов во внебюджетные фонды - ПФР, ФОМС и ФСС [11].

В дальнейшем это снижение может продолжиться и в совокупности со снижающимися ценами на экспортируемое сырье это усугубит состояние экономики в целом. Таким образом, возможными путями решения сложившейся ситуация для стабилизации экономики и поддержания граждан являются использование средств фонда национального благосостояния (ФНБ) (12,14 трлн рублей (173,54 млрд долларов США) или 10,7\% внутреннего валового продукта (ВВП) по состоянию на 01.07.2020) [14], передача части обязательств внебюджетных фондов на федеральный бюджет или изменение структуры страховых взносов для большей гибкости механизма финансирования. Но вне зависимости от принимаемых решения, можно с уверенностью сказать, что это даст лишь кратковременный эффект. Возможности по привлечению дополнительных ресурсов, в том числе из ФНБ лимитированы, в случае сокращения объема ликвидных средств ФНБ ниже 5\% ВВП ежегодный объем использования средств Фонда на покрытие дефицитов федерального бюджета и бюджета Пенсионного фонда Российской Федерации не может превышать объем, эквивалентный 1\% ВВП. [5]

Подытоживая рассмотренные проблемы, очевидно, что для преодоления текущей неблагоприятной ситуации необходимо не только изыскивать источники покрытия выпадающих доходов, но и прорабатывать механизмы для долгосрочного развития экономики с учётом тенденций последних лет по оптимизации механизмов хозяйствования. Это возможно только при переориентации существующей экономической модели страны на инновационный путь развития. Основными причинами, усугубляющими сложившуюся ситуацию, являются низкий уровень влияния инновационных разработок на экономику страны, недостаточные стимулы в том числе со стороны властей для изменения сложившейся ситуации $[2,3,16]$. Для преодоления сложившегося кризиса, формирования нового импульса для устойчивого развития экономики страны в среднесрочной и долгосрочной перспективе необходимо кардинальным образом пересмотреть существующие отраслевые стратегии повышения инновационного развития экономики РФ, В том числе с учётом опыта стран, которые успешно конкурируют с мировыми лидерами в инновационных сферах (Китай, Южная Корея и др). Выбранный путь для трансформации экономики представляется оптимальным с учётом сложившейся и прогнозируемой экономической конъюнктуры, что позволит достичь резкого роста экономики Российский Федерации в посткризисный период. Ключевое преимущество, благодаря которому можно достичь успеха - это инновации управления инновационными процессами, а не инновации управления производства, которые лежали в основе предыдущей промышленной революции, изучение данного направления - всё более актуальная научная задача наших дней.

ЛИТЕРАТУРА

1. Интервью Джим Роджерса «Джим Роджерс спрогнозировал окончание кризиса не ранее 2021 года» [Электронный pecypc] URL: https://cutt.ly/OtUDzUu Дата обращения 31.05 .2020

2. Лущай А.А., Агалакова А.В. Механизм трансфера наукоемких технологий // Актуальные проблемы авиации и космонавтики. 2013. № 9.

3. Максимов Н.Н. Теоретические основы инновационной деятельности // Молодой ученый. 2013. № 10.

4. Мануков С.В китайской экономике впервые за полвека может начаться спад [Электронный ресурс] URL: https://expert.ru/2020/03/5/kitaj/ , дата 0бращения 05.06.2020. 
5. Министерство финансов РФ информационное сообщение «0 механизме бюджетного правила при снижении цен на нефть ниже базового уровня» [Электронный ресурc] URL: https://www.minfin.ru/ru/presscenter/?id4=36986-informatsionnoe_soobshchenie, дата 0бращения 09.07.2020.

6. Попов В. Замедление Китая: судьба или выбор? [Электронный ресурс] URL: https://expert.ru/expert/2020/13/zamedlenie-kitaya-sudba-ili-vyibor/ Эксперт» №13 2020, дата обращения 25.07.2020.

7. Ткачёв И. Экономисты оценили падение деловой активности в России из-за карантина [Электронный ресурc] URL: https://www.rbc.ru/economics/31/03/2 020/5e82072b9a7947cd365957bf, дата обращения 31.06.2020.

8. Уотсон Д. Банки России и СНГ находятся под давлением коронавируса и резкого падения цен на нефть, рейтинговое агентство Fitch [Электронный ресурс] URL: https://www.fitchratings.com/site/pr/10115443, дата обращения 31.03.2020.

9. Коултон Б. Коронавирусный кризис сокрушает рост мирового ВВП, рейтинговое агентство Fitch [Электронный ресурc] URL: https://whttps://www. fitchratings.com/site/pr/10115443, дата обращения 19.04.2020.

10. Шваб К. Четвертая промышленная революция// Бомбора, 2016 г, ISBN: 978-5-699-90556-0.

11. Якушев Е., Синявская 0., Столяров А. «Влияние пандемии COVID-19 на институты социального страхования» Институт социальной политики НИУ ВШЭ 2020 г. [Электронный ресурс] URL: https://cutt.ly/OtUDrji, дата обращения 30.05.2020.

12. Dessi, R., Zhao, X. Overconfidence, stability and investments. Journal of Economic Behavior and Organization, 145, 474-494, 2017.

13. Глобальный инновационный индекс 2019 [Электронный ресурc] URL: https://www.wipo.int/edocs/pubdocs/ru/wipo_pub_gii_2019_keyfindings.pdf Дaта обращения 14.05 .2020

14. Официальный сайт Министерства Финансов [Электронный ресурс] URL: https://minfin.gov.ru/ru/perfomance/nationalwealthfund/statistics/?id_65=27068obem_fonda_natsionalnogo_blagosostoyaniya Дата обращения 01.08.2020

15. ВВП Китая рухнул на рекордные 7\% из-за коронавируса [Электронный ресурс] URL: https://www.rbc.ru/economics/17/04/2020/5e9931b09a794736e1a18b df Дата обращения 17.05 .2020

16. Инновации в России — неисчерпаемый источник роста / McKinsey\&Company [Электронный ресурc] URL: https://www.mckinsey.com/ /media/McKinsey/ Locations/Europe\%20and\%20Middle\%20East/Russia/0ur\%20Insights/Innovations\%20in\%20Russia/Innovations-in-Russia_web_Iq-1.ashx

( х Хавин Дмитрий Валерьевич (odonngasu@yandex.ru), Беккер Павел Райнгольдович (BeckerPR@yandex.ru).

Журнал «Современная наука: актуальные проблемы теории и практики»

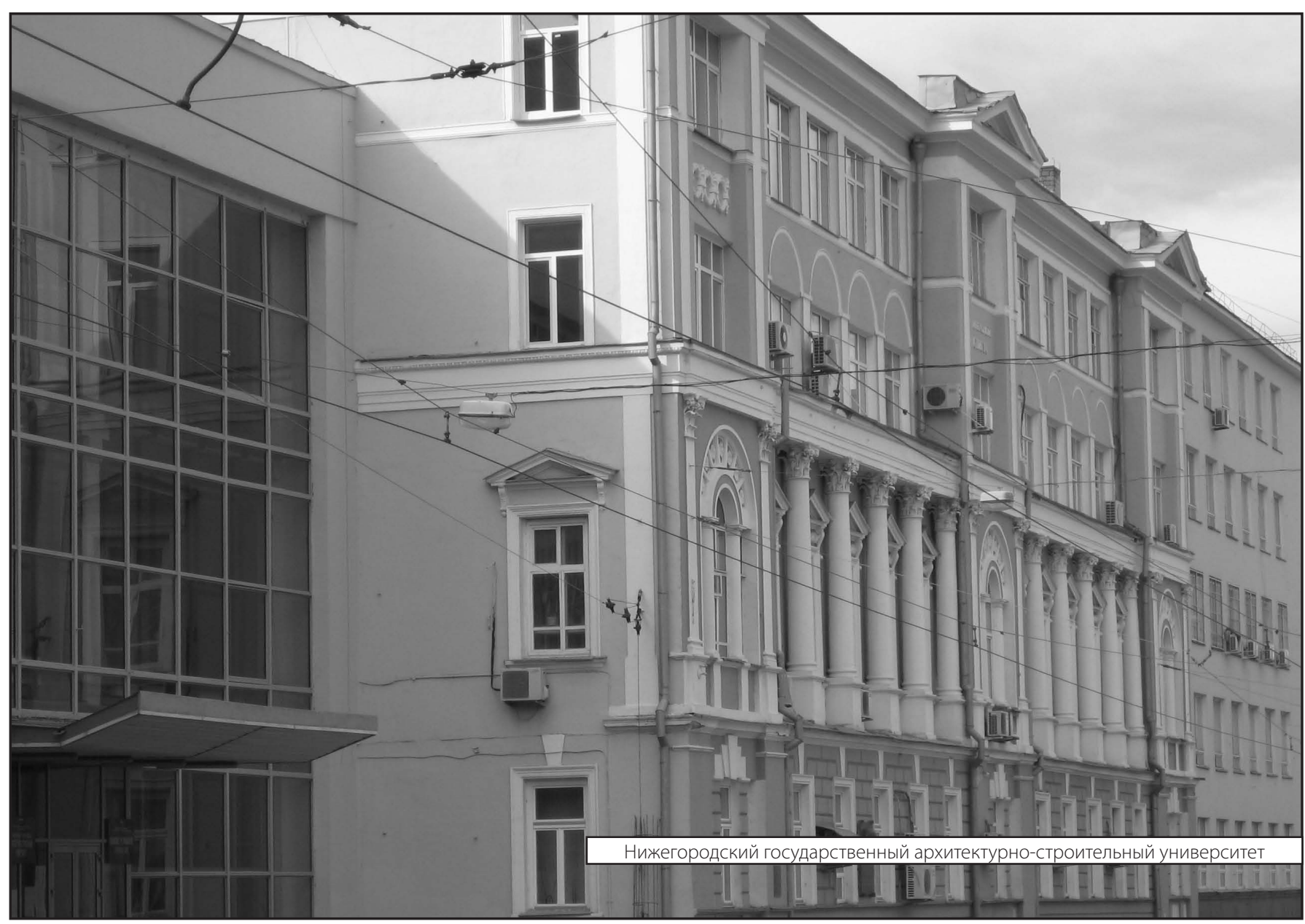

